\title{
Muerte súbita por sepsis meningocócica: diagnóstico post mórtem
}

\section{Sudden death from meningococcal sepsis: postmortem diagnosis}

\begin{abstract}
Resumen
La presentación más común de la enfermedad meningocócica es la meningitis, con una tasa de incidencia de 0,92 por 100.000 habitantes y una letalidad del 40,3\% en España. Un cuadro meníngeo puede cursar con síntomas inespecíficos como la cefalea, entre otros, de tal forma que en ocasiones progresa rápidamente en cuestión de horas y provoca la muerte del paciente antes de haber recibido una atención médica adecuada. Además de la meningitis clásica, el meningococo produce una enfermedad sistémica que incluye la sepsis meningocócica y la coagulopatía intravascular diseminada. En pacientes con sepsis meningocócica se ha descrito el síndrome de Waterhouse-Friderichsen, que se caracteriza por hemorragia suprarrenal bilateral, coagulación intravascular diseminada e hígado de shock, y que produce una bacteriemia grave. Esta combinación provoca un shock fulminante y, si no se trata, puede producir muerte súbita. Presentamos el caso de una paciente con odinofagia, fiebre, vómitos y deposiciones diarreicas de 24 horas de evolución, que a pesar de recibir asistencia médica ambulatoria y hospitalaria fallece como consecuencia de una sepsis fulminante por Neisseria meningitidis y síndrome de Waterhouse-Friderichsen no diagnosticado clínicamente.
\end{abstract}

Palabras clave: Muerte súbita. Síndrome de Waterhouse-Friderichsen. Sepsis meningocócica. Microbiología post mórtem. Neisseria meningitidis.

\begin{abstract}
The most common presentation of meningococcal disease is meningitis, with an incidence rate of 0.92 per 100,000 inhabitants and a mortality rate of $40.3 \%$ in Spain. Meningeal disease may present with nonspecific symptoms such as headache, among others, sometimes progressing rapidly to a fatal outcome before the patient receives adequate medical care. Besides classical meningitis, Neisseria meningitis produces a systemic disease that includes meningococcal sepsis and disseminated intravascular coagulopathy. In patients with meningococcal sepsis the WaterhouseFriderichsen syndrome is described, which is characterized by bilateral adrenal hemorrhage, intravascular coagulation and shock liver, producing a severe bacteremia. This combination causes a fulminant shock and, if untreated, it may cause sudden death. We report the case of a female patient with sore throat, fever, vomiting and diarrhea of 24 hours of evolution. Despite receiving inpatient and outpatient medical care, she died as a result of $N$. meningitidis fulminant sepsis and clinically undiagnosed Waterhouse-Friderichsen syndrome.
\end{abstract}

Key words: Sudden death. Waterhouse-Friderichsen syndrome. Meningococcal sepsis. Postmortem microbiology. Neisseria meningitidis.

\section{Introducción}

La presentación más común de la enfermedad meningocócica es la meningitis, ya que supone un $30-60 \%$ de la enfermedad meningocócica invasiva, como reflejo del tropismo meníngeo característico de Neisseria meningitidis ${ }^{1}$. Entre los patógenos más co- munes causantes de meningitis en todo el mundo se encuentran actualmente Streptococcus pneumoniae, N. meningitidis y Haemophilus influenzae serotipo b, con una incidencia variable en el tiempo y según la localización geográfica y los grupos de edad². Con Haemophilus en declive, N. meningitidis se ha convertido en el líder de los patógenos meníngeos en los

\section{Beltrán ${ }^{1}$}

PJ. Pérez-Jorge ${ }^{2}$

A. Fernández-Rodríguez ${ }^{3}$

${ }^{1}$ Unidad Docente de Medicina Legal y Forense. Facultad de Medicina. Universidad de Córdoba.

Servicio de Patología Forense. Instituto de Medicina Legal de Córdoba. 3Servicio de Biología. Instituto Nacional de Toxicología y Ciencias Forenses. Madrid.

\section{Correspondencia:}

Cristina M. Beltrán Aroca Unidad Docente de Medicinal Legal y Forense. Facultad de Medicina. Universidad de Córdoba Avda. Menéndez Pidal, s/n. 14004 Córdoba

E-mail: h12bearc@uco.es

Fecha de recepción:

18.JUL.2014

Fecha de aceptación: 31.DIC.2014 
países en desarrollo, pero sigue siendo un importante problema de salud en Europa y EE.UU. Según el Centro Nacional de Epidemiología, el número total de casos confirmados de enfermedad meningocócica en España, durante la temporada 2010-2011, fue de 425, con una tasa de incidencia de 0,92 por 100.000 habitantes, un $4 \%$ inferior a la anterior. Se notificaron un total de 64 defunciones, de las cuales las causadas por $N$. meningitidis serogrupo C fueron 27, con una letalidad del $40,3 \%^{3,4}$.

La nasofaringe humana es el único reservorio natural de este microorganismo, y la transmisión se produce de una persona a otra a través de las secreciones respiratorias ${ }^{1}$. El intervalo de tiempo entre la adquisición del microorganismo y la infección clínica es de 10 días o incluso menos. Tras la colonización de la nasofaringe, el meningococo invade la mucosa y penetra en el torrente sanguíneo ${ }^{4}$. Un cuadro meníngeo puede cursar con síntomas inespecíficos como la cefalea, entre otros, y no ser diagnosticado a priori en urgencias. De tal forma, en ocasiones los síntomas progresan rápidamente en cuestión de horas y provocan la muerte antes de haber recibido una atención médica adecuada ${ }^{5}$. Además de la meningitis clásica, el meningococo produce con frecuencia una enfermedad sistémica fulminante que incluye la sepsis meningocócica y la coagulación intravascular diseminada (CID). En pacientes con sepsis meningocócica se ha descrito el síndrome de Waterhouse-Friderichsen, que se caracteriza por hemorragia suprarrenal bilateral, CID e hígado de shock, y además produce una bacteriemia grave ${ }^{6}$, aunque también se ha descrito su asociación con otros patógenos bacterianos ${ }^{7}$. Esta combinación provoca un shock fulminante y, si no se trata, puede producir muerte súbita.

La Organización Mundial de la Salud (OMS) estima al menos 500.000 nuevas infecciones sintomáticas por año en todo el mundo, lo que conlleva por lo menos 50.000 muertes. Se han descrito elevadas tasas de mortalidad y morbilidad asociadas a la meningitis bacteriana y al desarrollo secundario de una sepsis meningocócica ${ }^{8}$, ya que aproximadamente fallecen un $20-50 \%$ de los pacientes, además de las secuelas neurológicas en aquellos que sobreviven ${ }^{1,2}$.

Presentamos a continuación el caso de una paciente con odinofagia, fiebre, vómitos y deposiciones diarreicas de 24 horas de evolución, que a pesar de recibir asistencia médica ambulatoria y hospitalaria fallece como consecuencia de una sepsis fulminante por $N$. meningitidis y síndrome de WaterhouseFriderichsen no diagnosticado clínicamente.

\section{Exposición del caso}

\section{Antecedentes}

Mujer de 51 años de edad, con antecedentes de anexectomía unilateral por endometriosis, que tras 24 horas de evolución presenta fiebre de hasta $40{ }^{\circ} \mathrm{C}$ y odinofagia, remitiendo dicha sintomatología parcialmente con antiinflamatorios no esteroideos (AINE). Posteriormente aparecen vómitos y varias deposiciones diarreicas, con persistencia del síndrome febril, por lo que acude al centro de salud. Tras su valoración médica se prescribe tratamiento antitérmico y observación domiciliaria. Horas después sufre un empeoramiento del estado general, con hipotensión, refiriendo además cefalea y dorsalgia, por lo que se avisa al Servicio de Urgencias, que decide su traslado al hospital. En la exploración física destaca un regular estado general, taquipnea en reposo y taquicardia, no pudiendo captarse la presión arterial, así como tampoco resulta posible palpar los pulsos periféricos radiales. No presenta rigidez de nuca ni focalidad neurológica. Se realizan analítica y gasometría, que ponen de manifiesto una marcada leucocitopenia (2.440/ml) y acidosis metabólica $\left(\mathrm{pH} \mathrm{7,21;} \mathrm{HCO}_{3}\right.$ $14 \mathrm{mmol} / \mathrm{l} ; \mathrm{EB}-11,1 \mathrm{mmol} / \mathrm{l})$. La paciente ingresa en la Unidad de Cuidados Intensivos (UCI), donde a pesar de recibir tratamiento con corticoides y antibioticoterapia intravenosa empeora y fallece 2 horas más tarde, tras la realización de maniobras de reanimación cardiopulmonar. Debido a la evolución tórpida y al origen incierto del cuadro de shock, no se certifica la defunción.

\section{Hallazgos de la autopsia}

Como hallazgos significativos, en el examen externo destacan un exantema cutáneo generalizado, más acusado a nivel cefálico y en la cara anterior del tercio superior del tórax (Figura 1), y petequias en la conjuntiva tarsal de ambos párpados inferiores (Figura 2).

En el examen interno, macroscópicamente se aprecia:

- Congestión pulmonar moderada con edema pulmonar importante de características alveolar e intersticial con espuma bronquial.

- Derrame pleural derecho. Derrame pericárdico leve.

- Fluido exudativo en tejido subcutáneo retromamario de ambos lados, de aspecto purulento.

- Hígado de aspecto esteatósico con punteado hemorrágico.

- Ambas glándulas suprarrenales con médula de aspecto congestivo-hemorrágico (Figura 3). 

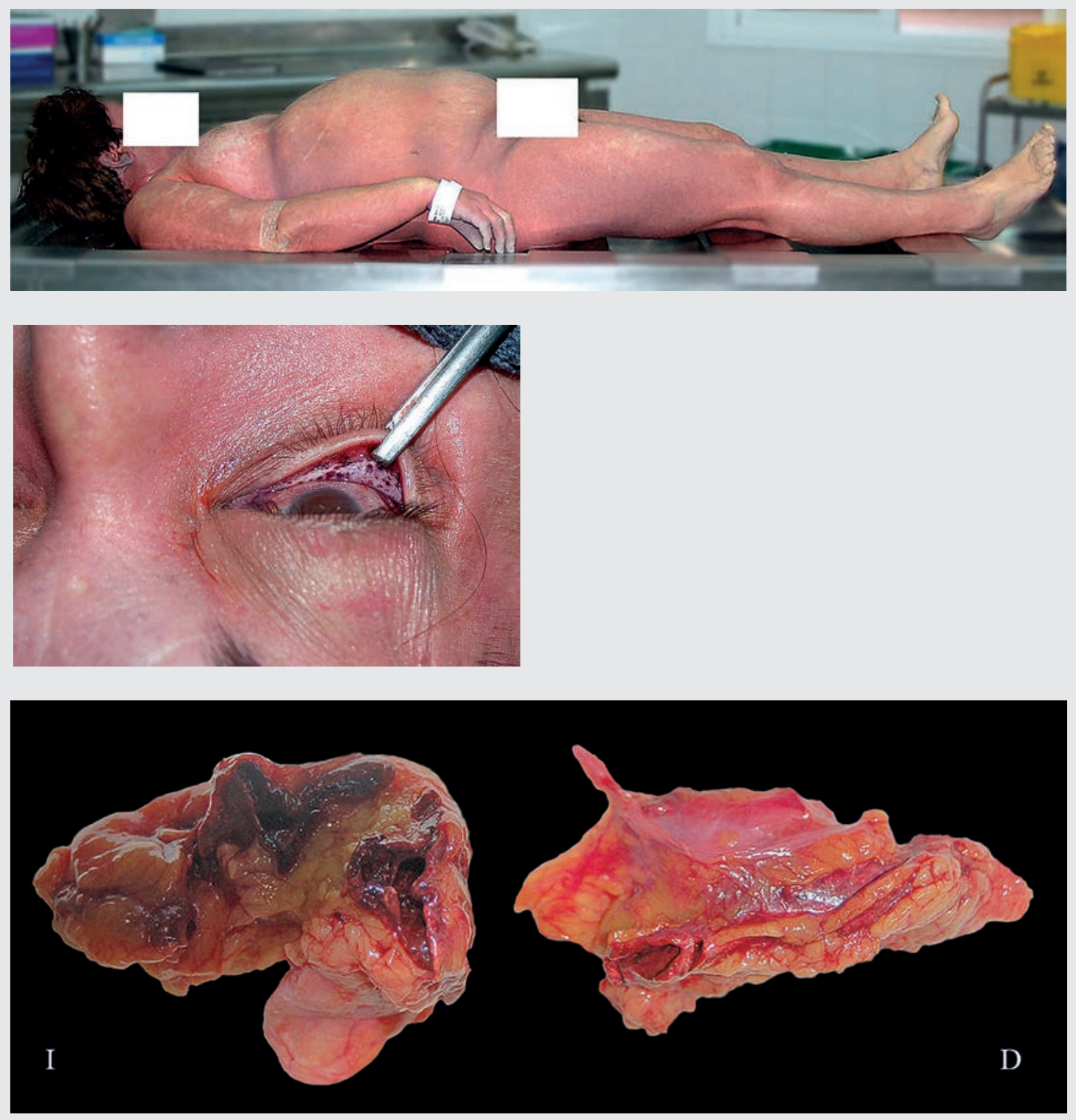

Figura 1.

Exantema cutáneo

generalizado.

Figura 2.

Punteado petequial en conjuntiva palpebral.

Figura 3.

Glándulas suprarrenales con aspecto congestivo-hemorrágico (I: izquierda; D: derecha).
- El encéfalo presenta un aspecto congestivo y edematoso generalizado, con hallazgo casual de un quiste en el lóbulo parietal izquierdo (Figura 4).

Se remiten para estudios toxicológico, microbiológico e histopatológico muestras de encéfalo, pulmón, hígado, bazo, suprarrenales, corazón, sangre periférica, humor vítreo, líquido pericárdico, contenido intestinal, frotis bronquial, derrame pleural e hisopo impregnado del exudado subcutáneo del pectoral derecho.
Los resultados del estudio microbiológico realizado mediante técnicas antigénicas, cultivo y reacción en cadena de la polimerasa (PCR) en tiempo real detectan la presencia de $N$. meningitidis serogrupo $\mathrm{C}$ en sangre periférica, suero y, en escasa cantidad, a nivel encefálico. Se realizan la caracterización epidemiológica de la cepa y el estudio de resistencia a antibióticos mediante concentración mínima inhibitoria (CMI). 
Figura 4

Encéfalo y cerebelo congestivos y edematosos.

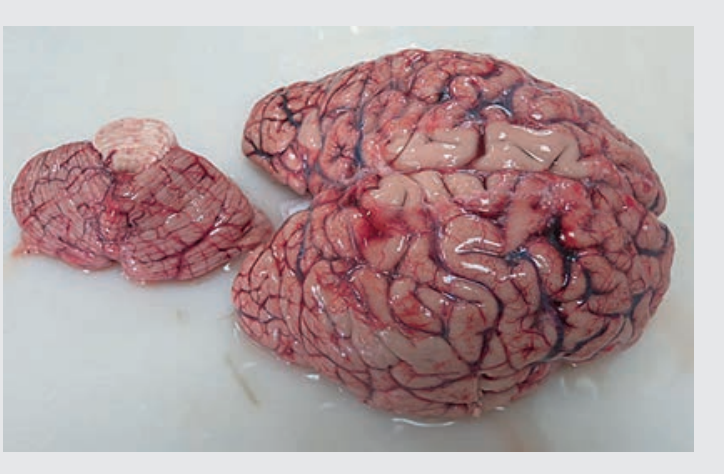

A nivel histopatológico se describen como hallazgos en el encéfalo congestión y edema, así como la existencia de un meningioma transicional-psamomatoso. Ambas suprarrenales presentan hemorragia grave; el hígado muestra signos sugestivos de shock en fase inicial, y a nivel renal hay alteraciones compatibles con CID. Además, se diagnostica esplenomegalia y cierta miocarditis neutrofílica.

El estudio toxicológico muestra tan solo resultado positivo para dipirona o metamizol.

Basándose en los hallazgos descritos se establecen como causas de la muerte: fallo multiorgánico producido por una septicemia fulminante por meningococo ( $N$. meningitidis serogrupo $C$ ) y síndrome de Waterhouse-Friderichsen.

\section{Discusión}

La sepsis meningocócica fulminante es quizá la forma más rápidamente letal de shock séptico que experimentan los seres humanos ${ }^{9}$. Su espectro clínico es amplio, y tanto la clínica como la evolución pueden ser impredecibles: la enfermedad febril inicial de carácter leve puede progresar a una enfermedad fulminante (síndrome de Waterhouse-Friderichsen), fallo multiorgánico y la muerte en cuestión de horas $^{1}$. Tal como ocurre en el caso que nos ocupa, se ha descrito que en las primeras 4-6 horas de la aparición de la enfermedad las manifestaciones no son específicas, ya que imitan los síntomas de las infecciones virales comunes ${ }^{10}$. Como sintomatología característica se refieren escalofríos, fiebre elevada, mareos, náuseas, cefalea o debilidad ${ }^{8}$. En el caso presentado, la paciente refiere al inicio fiebre, odinofagia, diarrea y vómitos, de menos de 24 horas de evolución, por lo que es importante tener en cuenta que la tríada clásica de fiebre, rigidez en el cuello y alteración del nivel de consciencia está presente en menos del $50 \%$ de los adultos a quienes se les ha diagnosticado una meningitis bacteriana ${ }^{1}$. Los signos y síntomas abdominales que presenta la paciente (dolor y deposiciones diarreicas, característicos de un cuadro de enteritis o enterocolitis) no son manifestaciones típicas de la sepsis meningocócica, aunque se recogen como signos de gravedad asociados a hemorragia gastrointestinal ${ }^{11} \mathrm{o}$ como síntomas sugestivos de una insuficiencia suprarrenal clínica ${ }^{12}$. Las petequias, como manifestaciones cutáneas más características, aparecen en el cuerpo en el 75\% de los casos y pueden coalescer, formando púrpura y lesiones intracutáneas ${ }^{8}$. Clínicamente, son las manifestaciones visuales de una CID y una coagulopatía de consumo. Aunque la CID es un fenómeno generalizado que afecta a todos los órganos, las glándulas suprarrenales son particularmente vulnerables, de tal forma que las hemorragias a este nivel pueden dar lugar a una insuficiencia suprarrenal transitoria ${ }^{13}$. El diagnóstico de hemorragia suprarrenal suele realizarse post mórtem durante la autopsia, debido a la falta de síntomas específicos que permitan sospecharla en vida ${ }^{11}$.

Se ha descrito, al igual que en nuestro caso, que cuando la presentación de la infección es atípica (con síntomas mínimos y/o inespecíficos) y especialmente agresiva puede evolucionar en muy pocas horas hacia un estado de coma, shock y finalmente producir la muerte, sin dar tiempo a un diagnóstico ante mórtem ${ }^{10}$, ya que las bacterias se reproducen con tal velocidad en la sangre que la siembra meníngea no ha tenido tiempo de desencadenar la inflamación del líquido cefalorraquídeo $(\mathrm{LCR})^{9}$. En estos supuestos es obligada la realización de la autopsia, de tal forma que el estudio histopatológico y el análisis microbiológico de las muestras de la necropsia serán clave para la detección temprana del agente infeccioso. Se recomiendan en primer lugar técnicas rápidas (30 minutos) como la aglutinación en látex, basada en la detección de antígenos bacterianos en suero, LCR y orina, que permite el diagnóstico de infecciones fulminantes por diversos agentes $(N$. meningitidis serogrupos A, B, C, Y y W135; S. pneumoniae; $H$. influenzae serotipo b; estreptococo $\beta$ hemolítico grupo B y Escherichia coli) 6,10,14. Al ser técnicas de carácter presuntivo, deben confirmarse posteriormente mediante cultivo bacteriano y/o análisis moleculares, destacando en este último caso la PCR en tiempo real de genes específicos de $N$. meningitidis y de sus serogrupos. Se ha demostrado en diversas series que, a pesar de que $N$. meningitidis es una bacteria frágil y muy sensible a los cambios de temperatura (la ideal es $36-37^{\circ} \mathrm{C}$ ), deshidratación y variaciones en el $\mathrm{pH}$, la utilización de PCR arroja resultados fiables incluso en aquellos casos en que existe putrefacción ${ }^{15,16}$. 
Durante la autopsia del supuesto planteado, la presencia de una erupción cutánea eritematosa y los antecedentes clínicos de síndrome febril con vómitos y diarrea orientan en un primer momento hacia un posible cuadro séptico, sin descartar una toxiinfección alimentaria. Sin embargo, los exámenes macroscópico e histopatológico ponen de manifiesto una hemorragia grave a nivel de ambas suprarrenales, confirmando el diagnóstico de síndrome de Waterhouse-Friderichsen. Tal como se ha recogido en algunas series ${ }^{11}$, la asociación de este síndrome con un shock séptico fulminante es la causa del fallo multiorgánico que finalmente provocó la muerte de la paciente. Entre los hallazgos destacan la presencia de miocarditis, que también se relaciona en algunos casos con un shock cardiogénico agudo como causa de muerte ${ }^{1}$, y a nivel encefálico edema y congestión, resaltando sin embargo la ausencia de exudado meníngeo purulento ${ }^{8}$.

Como conclusión, desde el punto de vista médicoforense, ante la sospecha de una infección bacteriana fulminante resulta necesario realizar un enfoque multidisciplinario adecuado basado en la revisión de los antecedentes clínicos y el estudio microbiológico e histopatológico, que permita alcanzar un diagnóstico post mórtem acertado. En este contexto, hay que prestar especial atención en los casos de muerte súbita y en las investigaciones por mala praxis, en especial cuando los síntomas inespecíficos o atípicos de la infección progresan rápidamente a un desenlace fatal y el único hallazgo post mórtem es la hemorragia suprarrenal. Incluso, en ocasiones, las manifestaciones cutáneas pueden estar por completo ausentes y la hemorragia suprarrenal puede ser focal y tan sólo observada microscópicamente, por lo que el diagnóstico definitivo va a depender de los resultados microbiológicos y de los hallazgos patológicos.

Los autores declaran no tener ningún conflicto de intereses.

\section{Bibliografía}

1. Strelow VL, Vidal JE. Invasive meningococcal disease. Arq Neuropsiquiatr. 2013;71(9B):653-8.

2. Kasanmoentalib ES, Brouwer MC, Van de Beek D. Update on bacterial meningitis: epidemiology, trials and genetic association studies. Curr Opin Neurol. 2013;26(3):282-8.

3. Grupo de Trabajo MenCC 2012, de la Ponencia de Programas y Registro de Vacunaciones. Revisión de la pauta de vacunación frente a enfermedad meningocócica por serogrupo C. Comisión de Salud Pública del Consejo Interterritorial del Sistema Nacional de Salud. Madrid: Ministerio de Sanidad, Servicios Sociales e Igualdad; 2013.

4. Roos KL, Van de Beek D. Bacterial meningitis. Handb Clin Neurol. 2010;96:51-63.

5. Dix J. Color atlas of forensic pathology. Florida: CRC Press; 2000.

6. Fernández-Rodríguez A, Morentin Campillo B. Protocolo de actuación forense ante la sospecha de meningitis bacteriana y shock séptico fulminante. Cuad Med Forense. 2005;37:7-19.

7. Ventura F, Bonsignore A, Portunato F, Orcioni GF, Varnier OE, De Stefano F. A fatal case of streptococcal and meningococcal meningitis in a 2-years-old child occurring as Waterhouse-Friderichsen syndrome. J Forensic Leg Med. 2013;20(6):678-82.

8. DiMaio VJM, DiMaio DJ. Forensic pathology. 2nd ed. Florida: CRC Press; 2001.

9. Wetzler LM. Infecciones meningocócicas. En: Fauci AS, Braunwald E, Kasper DL, Hauser SL, Longo
DL, Jameson JL, Loscalzo J, editores. Harrison: Principios de medicina interna. Vol. I. México: McGraw-Hill Interamericana; 2009. p. 908-14.

10. Fernández-Rodríguez $A$, Vázquez JA, Suárez-Mier MP, Aguilera B, Ballesteros S, De la Fuente L, et al. Latex agglutination for bacterial antigens and meningococcus PCR: two useful tools in legal sudden deaths. Forensic Sci Int. 2005;147(1):13-20.

11. Stella-Silvaa N, Oliveiraa SA, Feldman-Marzochib KB. Meningococcal disease: clinicopathological correlation. Enferm Infecc Microbiol Clin. 2003; 21(10):557-62.

12. Tormos LM, Schandl CA. The significance of adrenal hemorrhage: undiagnosed WaterhouseFriderichsen syndrome, a case series. J Forensic Sci. 2013;58(4):1071-4.

13. Van Deuren M, Brandtzaeg P, Van der Meer JW. Update on meningococcal disease with emphasis on pathogenesis and clinical management. Clin Microbiol Rev. 2000;13(1):144-66.

14. Morentin B, Fernández-Rodríguez A. Muerte súbita por meningitis bacteriana y choque séptico: aportaciones del diagnóstico del estudio necrópsico. Enferm Infecc Microbiol Clin. 2006;24(7):469-74.

15. Dissanayake DM, Waduge PC, Chandrasiri NS, Ediriweera RC. Isolation of Neisseria meningitidis from cadaveric blood. Ceylon Med J. 2013;58(1):35-6.

16. Maujean G1, Guinet T, Fanton L, Malicier D. The interest of postmortem bacteriology in putrefied bodies. J Forensic Sci. 2013;58(4):1069-70. 